\title{
'People are not plants, but both need to grow': qualitative analysis of the new ecological paradigm scale for children
}

\author{
Helen Kopnina
}

Published online: 11 May 2012

(c) The Author(s) 2012. This article is published with open access at Springerlink.com

\begin{abstract}
One of the most popular measures of ecological worldview, predicting environmental attitudes and behaviours, is the New Ecological Paradigm (NEP) scale. Since the adoption of the scale for the use among children by Manoli, Johnson and Dunlap in 2007, it has been applied to measure children's environmental attitudes across cultures. There is however some controversy about the cross-cultural applicability and the relevance of the NEP scale items. The aim of this article is to contribute to the research about environmental views of children from an anthropological view. In the case study, 59 voluntarily participating students aged between ten and 12 years were interviewed in order to learn about their understanding of the NEP items for children. Group discussions were carried out to discover divergent views on the items, followed by in-depth interviews with 15 pupils. The excerpts from these discussions suggest that children experience ambiguity in interpreting the items of the NEP scale. It is concluded that the effective interpretation of scientific facts requires more nuanced and context-specific approach. The author asks for more qualitative, critical probing in addition to the application of the NEP scale in order to get a fuller response and deeper understanding of environmental attitudes of children.
\end{abstract}

Keywords Case study - Children - Ecological worldview · Environmental attitudes · Focus groups · Interviews · New Ecological Paradigm (NEP) scale

\section{H. Kopnina $(\square)$}

Amsterdams Institute voor Arbeids Studies (AIAS), University of Amsterdam, Plantage Muidergracht 12, 1018 TV Amsterdam, The Netherlands

e-mail: alenka1973@yahoo.com; h.kopnina@hhs.nl

\section{Introduction}

Studies of environmental views come from a wide variety of fields including sociology, psychology, teacher education and the life sciences (see for example Wals 2007; Chawla 1999; Kahn and Kellert 2002; Pilgrim et al. 2008). While anthropology has historically dealt with subjects ranging from native belief systems and the interaction between humans and their environment, the measurement of environmental attitudes and behaviours were left to the more quantitative social sciences and contributions by anthropologists are surprisingly scarce (Efird 2011; Kopnina and Shoreman-Ouimet 2011; Kopnina 2012a).

The aim of this article is to contribute to the research about environmental views of children from an anthropological view and to enrich the interdisciplinary depository of studies of the cultural variants in perception of environment in children. Studies measuring environmental awareness by school and college students are still limited to sociological, pedagogical or psychological studies (Miller 1975; Kahn 1999). In contrast to the wealth of nonanthropological scholarship on children's environmental awareness, 'anthropologists have paid little attention to the role of children in the process of learning and transforming environmental knowledge... an interesting (and sad) lapse given the general notion that culture is learned' (Efird 2011). Instead of providing a complementary perspective on quantitative studies, anthropologists seemed to have shied away from any 'measurements' and preferred to proceed with their specialty of case studies, and participant observation in domains unoccupied by their more numerically prone colleagues. Yet, as the author, herself an anthropologist, would argue, there is enough to be added by anthropologists to the existing scholarship of environmental values that could strengthen, complement and 
sometimes challenge more 'exact' social sciences (Kopnina 2011b).

After a summary of previous approaches to the measurement of environmental attitudes and behaviour of children and young adults, I will focus on the New Environmental Paradigm scale. A newly developed version of the scale for children and cross-cultural applications of the measure will then be discussed, followed by presentation of the case study.

\subsection{Measuring environmental attitudes and behaviour in children and young adults}

From the nineteen eighties, studies of environmental attitudes in children and young adults were concerned with perceptions of specific local environmental issues, such as energy use at home (Pallak et al. 1980) or pollution (Iozzi 1981). More recent efforts have moved away from local approaches to broader conception of our relationship to nature (Mayer and Frantz 2004:503) such as cultural values and environment (Stern and Dietz 1994; Stern 2000).

Greater interest in environmental education has emerged as even short educational programs were proved to stimulate environmental awareness in children (Evans et al. 2007; Manoli et al. 2007) and college students (Rideout 2005). The effectiveness of environmental education was sometimes tested by measuring environmental attitudes, by using a higher-order model of ecological values (Bogner and Wiseman 2003; Johnson and Manoli 2008). Translation from beliefs, attitudes, views and values to actual behaviour was developed by Stern et al. who pioneered their widely used value-belief-norm (VBN) model of environmental concern and behaviour (1995 and 1998). Various techniques were used for the study of environmental values and behaviour in children and adolescents, such as a behaviour-based attitude scale, which is grounded in people's recall of their past behaviour (Kaiser et al. 2007).

Psychologists, focusing on the issues of human choices and actions, had much to contribute to the issues of environmental sustainability (Mayer and Frantz 2004:503). Social psychologists have applied knowledge from the research reviews on attitudes (e.g. Rauwald and Moore 2002), conversion of environmental intentions to environmental behaviours (Gardner and Stern 2002; Evans et al. 2007; Kaiser 2004), responsible environmental behaviour (Hines et al. 1987), behaviour-based environmental attitudes (Kaiser et al. 2007), moral reasoning and persuasion (Gonzales et al. 1988; Davis 1995; Kellert 1995), reasoning about environmental dilemmas (Kahn and Kellert 2002), and normative influence (Cialdini et al. 1990).
A number of measuring scales were developed to measure environmental knowledge, attitudes and behaviour. Maloney et al. (1975) developed a scale measuring environmental behavioural commitments, affective states and knowledge in adults. Wiegel and Wiegel (1978) have tested and endorsed the reliability and validity of the Environmental Concern Scale, a 16-item Likert scale assessing respondents' concerns about conservation and pollution issues. The General Environmental Behaviour (GEB) scale was developed by Kaiser et al. (Kaiser 1998; Kaiser and Biel 2000), originally consisting of 50 yes/no questions about engagement in discrete environmental activities varying in relative difficulty.

Connectedness to nature, or 'the extent to which an individual includes nature within his/her cognitive representation of self' (Schultz et al. 2004), was measured by the 'inclusion of nature in the self' (INS) scale. This is a single-item measure consisting of seven pairs of circles, ranging from 'me' to 'nature', whereas the respondents are asked to choose the pair that best represents their sense of the world. However, INS was criticized for being unreliable as it includes only a single-item scale. Schultz et al. (2004) also developed a modified version of INS, called the implicit associations test (IAS). IAS participants are instructed to categorize two different types of words, distinguishing between words that suggest 'me' (I, mine) and 'not me' (it, their). They also distinguish between 'nature' words (animals and trees) and 'built' words (car and city). The extent to which one pairing is easier than the other indicates how 'me' (individual) implicitly associates himself with 'nature'. Drawing on INS and IAT, Mayer and Frantz have developed the connectedness to nature scale (CNS), a 'measure designed to measure an individual's affective, experiential connection to nature' (Mayer and Frantz 2004:504).

\section{The new ecological paradigm (NEP) scale}

One of the most popular measures of ecological beliefs or worldview in studies that use theoretical models predicting environmental attitudes and behaviours is the New Ecological Paradigm (NEP) scale (Dunlap 2008). The scale is a widely used measure of people's shifting worldviews from a human dominant view to an ecological one, with humans as part of nature. The Dominant Social Paradigm (DSP), positing endless progress, growth, abundance and attitudes contributing to environmental degradation, is then opposed to the New Ecological Paradigm (NEP), which highlights the disruption of ecosystems caused by modern industrial societies exceeding environmental limits (Dunlap \& Van Liere 1978). 
Originally, the NEP scale consisted of three dimensions: the balance of nature, anthropocentrism and limits to growth (Dunlap \& Van Liere 1978). Later, additional elements were added to the scale, including human exemptionalism (the idea that human beings are exempt from constraints of nature) and ecocrisis (concerns about the occurrence of potentially catastrophic environmental changes (Dunlap 2008). The 15-item NEP scale consisted of eight items assessing an ecological—'humans as part of nature'-view and seven items assessing an anthropocentric_-'humans as rulers over nature'_-view. For example, 'humans are greatly mistreating the environment' is an ecological item, and 'humans will someday learn enough about how nature works to be able to control it' is an anthropocentric item. The NEP scale was applied in standardized, national-level NEP scores for 36 countries and correlated with a wide range of national characteristics and national-level scores on several social-psychological characteristics obtained from prior cross-national studies (Hawcroft and Milfont 2010). They found that nationallevel NEP scores were higher in countries that value harmony, collectivism, and intellectual and affective autonomy and lower in countries that endorse conservative and materialist values. They found that national-level NEP scores were positively related to the nations' endorsement of international environmental treaties.

\subsection{The NEP scale for children}

Based on the adult NEP scale, the New Ecological Paradigm scale for children was developed. Williams and McCrorie (1990) and Leeming and Dwyer (1995) developed the scale for measuring first to seventh graders' behavioural commitments, affective states and knowledge about the environment. However, this scale was based on outdated notions of environmental issues and included items that fall outside of children's volitional control (e.g. driving a car or choosing to take a bus). In addition, children within this age group might have difficulty comprehending these issues (Evans et al. 2007:638). Musser and Diamond (1999) have developed an assessment tool for young children that are age appropriate and included updated items related to current environmental problems. The instruments developed by Musser and colleagues are not based on theoretical and empirical research on environmental attitudes; attitudes and behaviours are combined into one index rather than being clearly distinguished (Evans et al. 2007). While the Musser et al. scale does use drawings to supplement verbal probes, their instrument is primarily semantic and does not include interactive game approaches that might be more fitting for the young children.
Manoli et al. (2007) used a standard Likert-type format of the NEP scale with additional word changes and made the scale more suitable for use with upper elementary school-aged children. The authors validated the modified NEP scale and suggested that a 3-dimensional modified NEP scale for children, with 10 instead of 15 items and revised wording, was appropriate for use with children aged 10-12 years. The researchers have applied the revised NEP scale to 672 children and examined these children's comprehension of the scale through interviews. The remaining 10 items, listed in Manoli et al. (2007:9), were as follows:

1. Plants and animals have as much right as people to live.

2. There are too many (or almost too many) people on earth.

3. People are clever enough to keep from ruining the earth.

4. People must still obey the laws of nature.

5. When people mess with nature, it has bad results.

6. Nature is strong enough to handle the bad effects of our modern lifestyle.

7. People are supposed to rule over the rest of nature.

8. People are treating nature badly.

9. People will someday know enough about how nature works to be able to control it.

10. If things don't change, we will have a big disaster in the environment soon.

However, the validation occurred only with American children, and many consequent studies have simply 'translated' the items of the scale into different languages.

\subsection{Critique of NEP}

However, NEP was criticized for being an inadequate measure of one's affective, experiential relationship to the natural world, as it seems to measure cognitive beliefs rather than affective experience (Mayer and Frantz 2004:505). The NEP scale for children items contains statements like 'We are getting close to having too many people on earth' (adopted by Van Petegem and Blieck 2006) that addresses a cognitive belief or factual knowledge about human population, not an emotional reaction to nature.

Secondly, there might be problems with the items applicability of the NEP scale. Manoli et al. concluded that caution must be used when interpreting the findings results because their research may not apply to children in other geographical locations. The authors are unable to generalize their results until additional research has been conducted with children from various backgrounds and geographical locations (Manoli et al. 2007:11). Lalonde 
and Jackson (2002) suggested that the NEP scale has outlived its usefulness and that the original NEP scale was overly simplistic and outdated. In their sample of highly educated professionals, Lalonde and Jackson found respondents who questioned the usefulness of the items in the scale. For example, a philosopher had problems with an item that included the statement 'that assumes humans and nature are distinct entities' (Lalonde and Jackson, p. 32). A biologist had a problem with another item and asked, '[A]re we talking about the physiological 'balance' of an individual organism, the ecological 'balance' of an ecosystem, or the 'balance' of fundamental laws of 'nature'?' (p. 34). Dunlap (2008) responded to this criticism by asserting that although these are understandable and intelligent responses from highly educated experts, it is difficult to imagine how one can phrase revised items to account for, for example, dynamic equilibria of ecosystems that could be used with representative samples of the general public whose technical knowledge of ecosystems is very limited. Thus, although Dunlap did not deny that individual items can be improved and updated, he found Lalonde and Jackson's (2002) critique to be unhelpful except to researchers who plan to conduct studies of highly educated and trained specialists in environmental issues (Dunlap 2008:10).

A significant criticism of the NEP scale also stems from its inability to address the 'deep ecology' perspective (Naess 1973) - the position in environmental ethics endorsing the view that all living things are alike in having intrinsic value, independent of their utilitarian usefulness to humans, thus embedding environmental ethics debate in the sphere of political theories of justice. Lundmarck (2007) has reasonably argued that many items on the NEP scale mostly measure shallow ecology perspective and reflect on mostly anthropocentric (human interest in protecting the environment) perspective.

\subsection{Cross-cultural applicability of NEP}

Another critique stems from the cross-cultural applicability of the NEP scale as the conceptualization of ecological worldviews may not be applicable outside of the developed Western nations (e.g. Chatterjee 2008). While some studies supported cross-cultural validity of the NEP scale (Kahn 1999; Bechtel et al. 1999; Hawcroft and Milfont 2010; Vikan et al. 2007; Bechtel et al. 2006), others seem to suggest that the items are not always 'translatable' outside of Western countries. A number of studies in Eastern European nations (Gooch 1995) and Latin American nations (e.g. Schultz and Zelezny 1998) have found lower levels of internal consistency and more difficulty with respondents' understanding of some items than have studies in the United States and Western European nations.
In industrialized societies, acceptance of the NEP implies a clear rejection of the anthropocentric views of the DSP, whereas in less industrialized societies, such as Mexico and Brazil, the distinction between the two worldviews may not be as clear-cut, implicating a holistic view of the humanenvironment relationship (Bechtel et al. 1999; CorralVerdugo and Armendáriz 2000).

In investigating cross-cultural environmental worldviews in children, Van Petegem and Blieck (2006) used the revised NEP scale for children aged 13-15. By administering the scale to children in Belgium and Zimbabwe, the authors found statistical differences between the two subgroups in their perspectives on human-environment interactions. No rigorous validation as by Manoli et al. (2007) occurred for this study. Van Petegem and Blieck, having conducted the studies among 613 Belgian and 524 Zimbabwean pupils, have only tested the comprehensibility of the scale 'with only a few children', reflecting that in future research, this should be validated more widely (Van Petegem and Bliek 2006:629). This is particularly surprising because the differences in perceptions as well as language barriers between West European and African nations can be very large. Deeper ethnographic study focusing on socio-cultural factors influencing the children's comprehension of the items scale seems warranted.

Another remarkable feature of such cross-cultural NEP scale studies is the interpretation of the differences in ecological views found across nations. In Van Petegem and Blieck's study, the authors found that children in Zimbabwe and Belgium display similar ecological worldviews, but differences occur at the human dominance dimension. Respondents in Belgium believe in human-nature equality, whereas Zimbabwean youngsters feel more dominant over nature and emphasize a utilitarian view of the environment. Unlike the Belgians, the Zimbabwean respondents displayed faith in the problem-solving abilities of science and technology and in the strength of nature to recover from human interference. In line with Korhonen and Lappalainen (2004) and Wells and Lekies (2006) theory, Van Petergem and Blieck speculate that these differences could be explained by distinct experiences of the natural world acquired in early childhood as these influence environmental concern. To support the hypothesis that the early childhood encounters with nature are crucial for the development of positive environmental values is supported by retrospective reports of environmentalists, which are replete with stories of early and memorable encounters with pristine nature (Kahn and Kellert 2002).

Remarkably, however, Van Petergem and Blieck failed to consider theories about the influence of social context (the influence of the children's worldviews by parents, peer groups) and political and institutional context (the role of government-sponsored information, media and education) 
on children's ecological attitudes. It seems that the comprehension of items on the NEP scale by the children needs further testing before the standardized answers can be usefully interpreted. An anthropological gaze could tackle these influences and help sociologists develop more grounded and justified analyses of cross-cultural differences. In referring to the complexities of human relationship with nature, anthropologists often evoke the broadly defined belief systems and local or indigenous knowledge in regard to conceptions of humans in their environment (Zarger 2010; Efird 2011; Anderson 2012). As environmental anthropologist Kay Milton (2002) stated, environmental anthropologists inquire how the process of cultural learning takes place, and how this learning is associated with our knowledge about and feelings towards the environment. Local knowledge of plants and animals, as well as the emotional bond and religious engagement with 'nature' or 'wilderness', gives way to social constructions of 'environment', as well as proliferation of built environments, where humans learn 'scientific facts' within enclosed spaces (Milton 2002). However, the local knowledge is all but gone, and anthropological work is rich in representations of local perceptions of environment and issues related to environment and health, cultural diversity and conservation, agriculture and many other subjects that do not attempt to measure but rather to understand the complexity of human attitudes to environment.

\section{Case study}

\subsection{Sample and methodology}

The study was conducted among 59 students between the ages ten and twelve recruited at two select schools in the Amsterdam area, the Netherlands, between April and June 2010. The follow-up interviews and observations were conducted with children (the total of 14 students) and their families between September 2010 and June 2011. Parental consent for participation was obtained. Six focus group meetings were held in groups of 10,12, 11, 9, 8 and 9 pupils in mixed age groups, followed up by 15 in-depth interviews with pupils.

The focal question of the focus groups and interviews was comprehension and discussion about 10 items of the NEP scale, presented above. The items were translated into Dutch, trying to keep the meaning of the English sentences as accurate as possible rather then literal 'word for word' translation. The items were read out one by one by the discussion leader. Having explained the goal of an exercise to the group, the researcher stayed in the 'background' allowing for spontaneous brainstorm. The aim of the focus group discussion was to tackle as well as divergent views.
In the cases of interviews, individual differences in perceptions were sought.

The aim of the follow-up interviews and observations was to establish the possible sources of information for the children by observing their interaction with parents, siblings and peers at home, as well as observing what they read, and whether they watched television, used Internet or other sources of information. Additionally, the follow-up stage was intended as a longitudinal study of changes in children's attitudes as well as living conditions and sources of information.

The data were processed through the qualitative analysis software MAXQDA, which helped to organize written out transcripts of interviews and focus group discussions into thematic clusters. Below, brief summary of the findings from the discussion of first six items of the NEP scale is presented. ${ }^{1}$

\section{Brief summary of the findings}

\subsection{Item 1. Plants and animals have as much right} as people to live

The word 'recht' ('right') in Dutch has similar connotations to the English word, and children picked out both the legal and the moral aspects of the 'right to live'. The majority of the children in the sample enthusiastically affirmed this item. However, some children have pointed out that while plants and animals have a right to live, humans have a right to eat them (girl, 11). The same girl pointed out that when 'people... or animals need to eat... because they are hungry, it's OK to eat other animals'. A boy of ten pointed out in an interview: 'lions also need to eat [other animals], like humans eat cows'. However, this boy has added, 'it's not OK to kill an animal just for fun as the animal also wants to live'. However, in the case of plants, children were more doubtful. As one ten-year-old boy said 'even vegetarians eat plants... You need to eat vegetables in order to survive. Vegetables are also plants'. These statements indicate that children recognize the moral 'right' of the non-human species to live, but this right is conditional on biological necessity (the need to eat, especially that of carnivorous animals).

Among the younger children, the right of life was also discussed in terms of justice-'if you kill (an animal),

\footnotetext{
${ }^{1}$ Due to the word limit constraints, detailed presentation of qualitative results and their analysis is not possible. Unfortunately, this is a limitation of ethnographic methodology which explains why so many anthropologists publish their findings in the book form. Present findings results and analysis are intended to give an indication of the issues that emerge during the qualitative testing of environmental attitude measuring scales and are not complete.
} 
another animal can get angry and strike back' (girl, 10). This was also reflected on humans: 'If one person kills (another one), he'll be put to jail. If you protect (another person or animal), they will protect you' (boy, 10).

In the focus group discussion, this remark led to a heated discussion about topics such as vegetarianism, omnivorous diets and carnivorous animals. The children of this age group have shown that they recognize 'intrinsic value' of non-human objects, as evident from the statements like 'Killing anybody, human or animal, is never good' and 'animals also have a right to live'. However, a girl of eleven noted that 'killing a person... is worse that killing an animal'. As a boy of eleven has shrewdly noted, almost quoting the Animal Farm by George Orwell ('some animals are more equal then others'): 'Some have more values then others... People have more value'. Another 11-yearold boy said in an interview: 'People are not plants, but both need to grow'.

\subsection{Item 2. There are too many (or almost too many) people on earth}

Translation of this item was almost literal ('Er zijn te veel (of bijna te veel) mensen op aarde). Children's comprehension of the population was quite ambiguous, as their cognitive beliefs did not always link population to environment. This item could be also valuable for testing anthropocentrism as the discussion turns from 'too many people' (implicitly 'for nature') to too many people for human wellbeing ('not enough food'). In one of the interviews, the girl (10) linked information about animals and forest to human population, but the connection was unclear to her:

Alice, 10: I think there are too many people... I don't know how many exactly. Maybe more than a billion. Interviewer: Is it good or bad?

Alice: I don't know.

Interviewer: Why do you think there are too many?

Alice: Because there isn't enough... space for everybody... Also for animals.

Interviewer: How do you know that?

Alice [uneasily] What do you mean?

Interviewer: That there isn't enough space?

Alice: Well, it's just that I saw forest being cut and all animals leaving... on TV... My dad says it's all... exaggerated.

Interviewer: $\mathrm{He}$ says there's enough space for everybody?

Alice: No, he says there is enough forest.

During the follow-up home visit, it appeared indeed that the father (having signed consent form for him daughter's participation) was inclined to think that 'all this environmental talk' was not 'healthy'. It would be interesting to find out how much of Alice's concern with growing population came from sources other then her father, how she evaluated these sources, and how other factors such as education helped to shape both her inaccurate knowledge (that there are about 1 billion people) and her present attitude.

Other respondents also felt uncertain about their knowledge, especially whether the population growth is 'good' or 'bad' and in relation to what (economy, on the one hand, and nature on the other hand). Some children exhibited 'transitional mentality' and the need for authoritative confirmation (in this respect, of the interviewer) of their beliefs.

\subsection{Item 3. People are clever enough to keep from ruining the earth}

Translation of 'ruining the earth' was somewhat complicated by the semantic of the expression 'kapot maken' (to break, to destroy and to ruin) which some younger children took literally to mean that people were 'breaking the earth'. One boy of 10 suggested that mining activities are 'making a hole in the earth', and another boy of ten thought that 'building houses breaks the crust of the earth'. Following this literal interpretation, the same boy has remarked that people are clever enough to build houses that do not 'break through the surface'. This concern with houses was clarified after the researcher's visit to the boy's home, realising that his family lived next to the on-going construction site. Considering that houses in Amsterdam are often built on what the boy himself called 'sinking ground' and occasionally need special ground works to keep them from 'sinking in', this literal analogy of 'breaking the earth' and being smart about construction made good sense in a Dutch context.

A few children have remarked that people ruin the earth through a number of activities such as cutting trees, building roads and 'spoiling the oceans'. In the group of older children, the girl of 11 had a discussion with the girl of 12 about the limitations of human ability to wisely exploit the ocean:

Simone, 11: I don't think humans are smart... with using the ocean... They keep getting too much fish out, and then there are spills... oil spills...

Anneke, 12: Yeah, but they do clean up the mess...

Simone: Yeah, but why make the mess in the first place?

Anneke: Yeah, well, I guess people just aren't too smart with... the oceans.

Children's belief in human technical ingenuity was somewhat mixed with the idea of 'stupidity' that goes hand in hand with technical progress. Many children thought that 
while some people were smart to use certain technology (for example, for 'cleaning up the mess'), others were less intelligent. This item also evoked (especially in boys) reminiscences of science fiction films in which the people or robots 'save the world' from imminent ruin brought by either by the people themselves or by machines created by people.

Climate change was also frequently mentioned in the interviews. Group discussion with the younger children showed, however, that the 10-year-olds had a rather superficial knowledge of the subject, mentioning that 'the earth gets warmer from the green house... that people make'. The older group of children who have 'covered' the topic at school gave more accurate facts and linked emissions from transport or commercial cattle to the changing global climate.

\subsection{Item 4. People must still obey the laws of nature}

Through the literal translation of the word 'law', 'laws of nature' was not clear in relation to human behaviour. A number of interesting questions pertaining to the children's understanding and definition of 'natural law' came to the fore. The children pondered what this law exactly refers to (is it the law that governs nature outside humans, does it include humans, or is it similar to the laws that govern humans themselves?) or what it can be opposed to (like 'human law'). Forefront during this group discussion of whether humans are like animals is interesting in the context of NEP theory, human exceptionalism and anthropocentrism. Various points were raised, ranging from the fear of nature's 'punishment' to the idea that humans are still vulnerable.

The 12-year-old girl believes both that the laws of nature apply less in industrial modern society due to technological innovations and that human society that cannot just be governed by natural laws. However, she also reflected that 'nature is still stronger' than the humans. Similarly, other children were not 'fixed' by one point of view or the other but rather shifts between the idea that either nature or humans are 'stronger' or may dominate each other.

Some children made a distinction between 'now' and 'then', with the present being dominated by the lack of religious beliefs and fear (of both god and nature, as the child eloquently put it), and with supermarkets and houses, the needs for hunting and shelter with associated dependency on environment are greatly reduced.

\subsection{Item 5. When people mess with nature it has bad results}

This appeared to be a leading question as both interviewed children and children in the focus group were quite unanimous in their support of this statement. However, when probed further, the question elicited a number of examples that demonstrated that the idea of 'messing with nature' had multiple connotations. Most of the ideas were centred around technology, extraction of resources and in surprisingly many cases (considering that neither of the children reflected learning about it in school) genetically modified organisms. A boy of 12 reflected in an interview:

People think they can make nature work... the way they want it to. They make things like... genetically modified cells, these cells can grow into super-plants, but these super-plants can kill other plants...People think that this way they will have more food to eat, because the super-plants are strong, they don't die if bugs eat them... They [people] make sprays [pesticides] to kill insects, but then you get poisonous fruits...

Having visited this boy's home, researcher has found out that the boy was an avid reader of National Geographic Junior, although he could not point out the issue that dealt with genetically modified crops. The boy also liked to watch the Discovery channel with his father, although since the programs were in English, he 'didn't like reading Dutch subtitles and just watched, because the images were so beautiful'. During the conversation at home, the boy's father exhibited strong opinion that humans 'should not presume that they can control nature'.

\subsection{Item 6. Nature is strong enough to handle the bad effects of our modern lifestyle}

Item 6 is originally formulated as 'The balance of nature is strong enough to cope with the impacts of modern industrial nations' and adopted for children to be phrased 'Nature is strong enough to handle the bad effects of our modern lifestyle'. This item is related to two separate notions. One is that of the 'impact of modern industrial nations' or 'effects of our modern lifestyle' (both perceived to have a negative effect on the environment). Another notion is that of nature being 'strong enough' to cope with or handle these negative effects.

Similar to the discussion of the previous items, it seems that the definitions of 'nature' and 'modern lifestyle' are contested in the group. Modern lifestyle was equated with pollution and consumption of global items like cars or telephones. In the focus group fragment, a question of scale is raised-whether the effects of 'modern lifestyle' are local or global, whether the 'modern lifestyle' itself extends to the whole planet or to specific localities, and whether nature has the uniform or differential capacity to 'handle' the bad effects of the modern lifestyle. 


\section{Reflection and discussion}

One of the findings of the research conducted by the author is that both the knowledge of population facts and their interpretation, as well as knowledge of nature's strength and resiliency, appear ambiguous in 10-12-year-old Dutch children. Some items, like the first one, are well suited for testing the anthropocentric-ecocentric continuum, while others, like items 3 and 6, may be less suited for it. The strength and resilience of nature are not necessarily linked by children to moral right, intrinsic values, perceived hierarchies, or other factors associated with the positions of deep or shallow ecology.

There were clear differences between the younger and older children's moral reasoning, which need to be further explored in longitudinal studies. For example, for younger children, the right to life was often perceived as practical or instrumental and was asserted through either anthropomorphic analogy ('animals wants to live' like human) or through the idea of reciprocity and possible punishment ('otherwise animals get angry'). Qualitative testing of the NEP scale can thus help tackling the stages of moral development in children.

\subsection{Sources of information}

As outlined by Evans et al. (2007), an important and unknown topic is the origin of young children's environmental attitudes and ecological behaviours.

Parental environmental attitudes and behaviours may eventually play a role in shaping the development of children's environmental attitudes and behaviours. How and when this occurs is an important question worthy of scholarly attention. How children come to frame environmental issues for themselves and then translate these beliefs into actions have critical implications for the future of our planet. Research on this important topic is truly in its infancy. Much important, path-breaking work lies ahead (Evans et al. 2007:657).

Sources of information ranged from school, parents, peers and media sources. Particularly, the follow-up stage of research with observation of children's families at home has revealed a number of overlapping and sometimes contradictory sources of information. Consistency within families' orientation and children's attitudes was observed, as well as correlations between family's choices and other sources of environmental information. For example, the more pro-environmental families (that engaged in recycling behaviour, used public transport, etc.) were more likely to buy a subscription for their children to National Geographic Junior journal or to watch Discovery channel programmes on television. However, more detailed and lengthy research is needed to assess the competing sources of information and level of importance that children attribute to them.

Similarly, the influence of political and educational context, such as the influence of the Dutch politics on the family-level view formation, needs further exploration. For example, the prominence of UNESCO's programme Decade of Education for Sustainable Development in Dutch curriculum and the presence of political Party for the Animals in the Netherlands coordinate certain educational activities that might have a bearing upon the children's school curriculum (Kopnina 2011a; Kopnina 2012b). Consequent research should also address intercultural differences by looking both at different ethnic segments of Dutch population as well as comparing cross-national qualitative studies of the NEP scale.

\subsection{Cross-cultural differences}

The differences between Dutch children's responses could be compared to those of children from other nations to deduce which of the responses are culturally conditioned and which are more 'universal'. Sources of information, as well as affective feelings, need closer examination. To do so, more lengthy methodology, such as participant observation of the children in home, school and other contexts, is needed.

Intercultural differences could be very important for understanding both cognitive and affective aspects of children's attitudes towards environment. For example, focus group discussion centred around both affective values and cognitive beliefs, as the children both 'felt' that there were 'too many people on earth' and had a certain value judgment about it—and in some cases, knew how many there were but did not feel it was either 'good' or 'bad'. It would be interesting to know what do Zimbabwean children, for example, think about the subject of overpopulation. The bigger question in this respect may be whether children from different cultures might have even more divergent than these interpersonal differences. Another question that needs to be explored in consequent research is how the information sources - the social, institutional or others-play a role in shaping the children's worldview, and how 'transitional mentality' may evolve as different cohorts of children are examined. While the NEP scale for children can be a very useful tool in measuring cognitive beliefs, the comprehension of items on the NEP scale by the children needs to be critically evaluated before the standardized answers can be usefully interpreted and analysed.

Obvious sample limitations can be noted, including small sample size, a self-selection bias (the fact that children and parents more interested in environmental issues volunteered to participate) and characteristic of the sample itself having to do with the fact that both schools were 
located in the predominantly 'white', well-to-do areas of Amsterdam. Studies of migrant groups in the Netherlands reveal large intergenerational behavioural differences between, for example, the Turks (see for example BengiArslan et al. 1997). Cross-cultural studies on children's attitudes in more ethnically heterogeneous schools might offer very divergent data and valuable insights.

\subsection{Potential anthropological contributions}

to the analyses of responses

In pondering how the Dutch children arrive at their environmental worldviews, we may propose a number of possible sources, all of which will need to be studied in greater detail in subsequent research. Social sources may include the parents, the peers and the educators. Media and literature sources may include study books, television, and (children's) journals and magazines. Institutional sources may include (environmental) education. Ecological and anthropological literature points out that children's environmental attitudes are conceived not just as a cognitive process, but also as a social and emotional process (Pretty 2002). According to the prominent environmental anthropologist Tim Ingold, knowledge is not simply passed on ready-made, but undergoes continual regeneration through guided rediscovery within social contexts of interaction between instructors and novices (Ingold 2007:16).

Historically in many traditional societies, older siblings played key roles in the transmission of environmental knowledge (Cajete 2000), and this may still be true in 'modern' countries such as the Netherlands. This 'has important implications for studies of environmental knowledge change' since 'it is likely that transmission of environmental knowledge may depend on sibling or peer teaching, particularly during early childhood' (Zarger 2010:358-359). In this context, intergenerational learning occurs in the form of an informal apprenticeship in which the child learns by interacting with others (Anderson 2012). The children from developed countries grow up with a very different kind of environmentalism, based on distant knowledge, rather than experience (Louv 2005). In analysing environmental attitudes in advanced industrial societies, anthropologists are also participating in the construction of local-level solutions by providing a window into the impacts of environmental change and globalization processes, and environmental perception and behaviour (Appadurai 1996). Rather than attempting to measure environmental awareness, anthropologists try to comprehend and describe its dependency on complex socio-cultural factors. Thus, understanding Dutch children's comprehension of the items of the NEP scale may be greatly strengthened by qualitative probing of the social and cultural context in which the children grow up.
The anthropological methodology of extended, intimate participant observation could provide a very effective way to document and assess the transmission and acquisition of environmental behaviour and belief (Baines and Zarger 2012). Consequent research needs to address these sources of information as well as differences across ethnic, level of education (of the parents) and age variables to understand how the environmental knowledge and attitudes of children are being formed.

Finally, limitations of small sample need to be noted, as well as the inevitable issue of robustness of qualitative research with its limited ability to generalize from richly detailed and contextually variable data. This limitation cannot be addressed easily because expanding the sample would mean even more difficulty analysing the data (and the consequential need to 'shrink' the findings to fit the article) and the danger of actually loosing this rich detail. On the other hand, a combination of qualitative and quantitative approaches, integrating statistical data derived from standard measuring scales and the ethnographic description of underlying socio-cultural conditions might provide a useful way forward.

\section{Conclusion}

In this article, we have investigated the theoretical background of studies of environmental attitudes in children. Considering the case study findings, it appears that children seem to have an ambiguous understanding of items from the NEP scales.

The author is not suggesting that the entire format of NEP is flawed and that it should be replaced with a more qualitative, ethnographic method of getting at environmental understandings and attitudes. However, findings of this study suggest that the combination of NEP scale AND qualitative, context-specific, critical probing (both at the social, as in focus groups, and individual, as with interviews, levels) would be better suited for testing both children's knowledge and affective states. Qualitative probing in cross-cultural contexts could also lead to a better phrasing of NEP items to get a fuller, clearer response.

In line with the observation that the NEP scale is not an adequate measure of one's affective, experiential relationship to nature because it measures cognitive beliefs rather than affective experience (Mayer and Frantz 2004:504), the author found that in case of Items 2, 4 and 6, that both the knowledge of scientific facts and their affective interpretation appear ambiguous in Dutch children. Also, Lundmarck's (2007) criticism of the NEP as somewhat inadequate of addressing the deep ecology spectrum of environmental ethics seems to be warranted as items 
related to resilience of nature seem unrelated to the children's sense of superiority of humans over other species.

It is too premature to analyse cross-cultural or crossnational studies using NEP scale for children without careful contextual qualitative analysis. Quantitative tools for eliciting and evaluating environmental attitudes such as NEP can be somewhat reductive and confusing unless supported by the in-depth ethnographic, context-specific studies. However, when strengthened by qualitative studies, measurements of environmental awareness can be a crucial starting point for deeper understanding of environmental attitudes in children and possibly for developing educational programmes.

Theories about the influence of the social context (the influence on children's worldviews of parents, peer groups) or political and institutional context (the role of the government-sponsored information, media and the education itself) need to be further addressed. Qualitative approach, probing children's beliefs as well as socio-cultural context in which environmental attitudes are formed, may add a great deal of depth to the otherwise sound system of measurement.

Open Access This article is distributed under the terms of the Creative Commons Attribution License which permits any use, distribution, and reproduction in any medium, provided the original author(s) and the source are credited.

\section{References}

Anderson EN (2012) Tales best told out of school: Traditional lifeskills education meets modern science education. In: Kopnina $\mathrm{H}$ (ed) Anthropology of environmental education. Nova Science Publishers, New York

Appadurai A (1996) Modernity at large: cultural dimensions of globalization. University of Minnesota Press, Minneapolis

Baines K, Zarger RK (2012) Circles of value: integrating Maya environmental knowledge into Belizean schools. In: Kopnina $\mathrm{H}$ (ed) Anthropology of environmental education. Nova Science Publishers, New York

Bechtel RB, Verdugo VC, de Queiroz Pinheiro J (1999) Environmental belief systems: United States, Brazil, and Mexico. J Cross Cult Psychol 30(1):122-128

Bechtel RB, Corral-Verdugo V, Asai M, Riesle AG (2006) A crosscultural study of environmental belief structures in USA, Japan, Mexico, and Peru. Int J Psychol 41:145-151

Bengi-Arslan L, Verhulst FC, van der Ende J, Eroi N (1997) Understanding childhood (problem) behaviours from a cultural perspective: comparison of problem behaviours and competencies in Turkish immigrant, Turkish and Dutch children. Soc Psychiatry Psychiatr Epidemiol 32(8):477-484

Bogner M, Wiseman FX (2003) A higher-order model of ecological values and its relationship to personality. Personality Individ Differ 34(5):783-794

Cajete G (2000) Native science: natural laws of interdependence. Clearlight Publishers, Santa Fe

Chatterjee DP (2008) Oriental disadvantage versus occidental exuberance: appraising environmental concern in India. Int Sociol 23:5-33
Chawla L (1999) Life paths into effective environmental action. J Environ Educ 31(1):15-26

Cialdini RB, Reno RR, Kallgren CA (1990) A focus theory of normative conduct: recycling the concept of norms to reduce littering in public places. J Pers Soc Psychol 58:1015-1026

Corral-Verdugo V, Armendáriz LI (2000) The 'new environmental paradigm' in a Mexican community. J Environ Educ 31(3): $25-31$

Davis JJ (1995) The effects of message framing on response to environmental communications. J Mass Commun Q 72:285-299

Dunlap RE (2008) The new environmental paradigm scale: from marginality to worldwide use. J Environ Educ 40(1):3-18

Dunlap RE, Van Liere KD (1978) The new environmental paradigm: a proposed measuring instrument and preliminary results. J Environ Educ 9(4):10-19

Efird R (2011) Learning the land beneath our feet: An anthropological perspective on place-based education in China. In: Kopnina H, Shoreman-Ouimet E (eds) Environmental anthropology today. Routledge, New York and Oxford

Evans GW, Brauchle G, Haq A, Stecker R, Wong K, Shapiro E (2007) Young children's environmental attitudes and behaviours. Environ Behav 39:645-659

Gardner G, Stern PC (2002) Environmental problems and human behaviour, 2nd edn. Allyn \& Bacon, Boston

Gonzales MH, Aronson E, Costanzo MA (1988) Using social cognition and persuasion to promote energy conservation: A quasi-experiment. J Appl Soc Psychol 18:1049-1066

Gooch GD (1995) Environmental beliefs and attitudes in Sweden and the Baltic states. Environ Behav 30:520-534

Hawcroft LJ, Milfont TL (2010) The use (and abuse) of the new environmental paradigm scale over the last 30 years: a metaanalysis. J Environ Psychol 30:143-158

Hines JM, Hungerford H, Tomera A (1987) Analysis and synthesis of research on responsible environmental behaviour: a meta analysis. J Environ Educ 18:1-8

Ingold T (2007) The trouble with "evolutionary biology". Anthropol Today 23(2):13-17

Iozzi LA (1981) Research in environmental education 1971-1980. ED 214762 (Columbus, OH, ERIC Clearinghouse for Science, Mathematics and Environmental Education)

Johnson B, Manoli CC (2008) Using Bogner and Wiseman's model of ecological values to measure the impact of an earth education programme on children's environmental perceptions. Environ Educ Res 2:115-127

Kahn PH Jr (1999) The human relationship with nature. MIT Press, Cambridge

Kahn PH, Kellert SR (eds) (2002) Children and nature. MIT Press, Cambridge

Kaiser FG (1998) A general measure of environmental behaviour. J Appl Soc Psychol 28:395-422

Kaiser FG (2004) Conservation behaviour. In: Spielberger C (ed) Encyclopedia of applied psychology. Academic Press, New York, pp 473-477

Kaiser FG, Biel A (2000) Assessing general ecological behaviour: a cross cultural comparison between Switzerland and Sweden. Euro J Soc Psychol 16:44-52

Kaiser FG, Oerke B, Bogner FX (2007) Behaviour-based environmental attitude: development of an instrument for adolescents. J Environ Psychol 27/3:242-251

Kellert SR (1995) The value of life. Island Press, Washington, DC

Kopnina H (2011a) 'Revisiting education for sustainable development (ESD): examining anthropocentric bias through the transition of environmental education to ESD'. Sustainable Development. Early view op http://onlinelibrary.wiley.com/doi/10.1002/sd. 529/abstract 
Kopnina H (2011b) What about that wrapper? Using consumption diaries in green education. In: Kopnina H, Shoreman-Ouimet E (eds) Environmental anthropology today. Routledge, New York and Oxford, pp 118-139

Kopnina H (ed) (2012a) Anthropology of environmental education. Nova Science Publishers, Inc, New York

Kopnina H (2012b) Education for Sustainable Development (ESD): the turn away from 'environment' in environmental education? Environ Educ Res. doi:10.1080/13504622.2012.658028

Kopnina H, Shoreman-Ouimet E (eds) (2011) Environmental anthropology today. Routledge, New York and Oxford

Korhonen K, Lappalainen A (2004) Examining the environmental awareness of children and adolescents in the Ranomafana region, Madagascar. Environ Educ Res 10(2):195-216

Lalonde R, Jackson EL (2002) The New Environmental Paradigm Scale: has it outlived its usefulness? J Environ Educ 33(4):28-36

Leeming FC, Dwyer W (1995) Children's environmental attitude and knowledge scale: construction and evaluation. J Environ Educ 26:22-31

Louv R (2005) Last child in the woods: saving our children from nature-deficit disorder. Algonquin Books of Chapel Hill, North Carolina

Lundmarck C (2007) The new ecological paradigm revisited: Anchoring the NEP scale in environmental ethics. Environ Educ Res 13(3):329-347

Maloney MP, Ward M, Braucht G (1975) A revised scale for the measurement of ecological attitudes and knowledge. Am Psychol 30:787-790

Manoli CC, Johnson B, Dunlap RE (2007) Assessing children's environmental worldviews: modifying and validating the New Ecological Paradigm Scale for use with children. J Environ Educ 38(4):3-13

Mayer SF, Frantz CM (2004) The connectedness to nature scale: a measure of individuals' feeling in community with nature. J Environ Psychol 24:503-515

Miller JD (1975) The development of pre-adult attitudes toward environmental conservation and pollution. School Sci Math 27:729-737

Milton K (2002) Loving nature: toward ecology of emotion. Routledge, New York

Musser LM, Diamond KE (1999) The children's attitudes toward the environment scale. J Environ Educ 30:23-30

Naess A (1973) The shallow and the deep: long-range ecology movement. A summary. Inquiry 16:95-99

Pallak MS, Cook DA, Sullivan JJ (1980) Commitment and energy conservation. In: Bickman L (ed) Applied social psychology annual. Sage, Beverly Hills, pp 235-253
Pilgrim SE, Cullen LC, Smith DJ, Pretty J (2008) Ecological knowledge is lost in wealthier communities and countries. Environ Sci Technol 42(4):1004-1009

Pretty J (2002) Agri-culture: reconnecting people, land, and nature. Earthscan, London

Rauwald KS, Moore CF (2002) Environmental attitudes as predictors of policy support across three countries. Environ Behav 34(2002):709-739

Rideout BE (2005) The effect of a brief environmental problems module on endorsement of the New Ecological Paradigm in college students. J Environ Educ 37(1):3-11

Schultz PW, Zelezny LC (1998) Values and proenviromental behaviour: a five-country survey. J Cross Cult Psychol 29: $540-558$

Schultz PW, Shriver C, Tabanico J, Khazian A (2004) Implicit connections with nature. J Environ Psychol 24:31-42

Stern PC (2000) Toward a coherent theory of environmentally significant behaviour. J Soc Issues 36:407-424

Stern PC, Dietz T (1994) The value basis of environmental concern. J Soc Issues 50:65-84

Stern PC, Dietz T, Guagnano GA (1995) The New Ecological Paradigm in social-psychological context. Environ Behav 27:723-743

Stern PC, Dietz T, Abel T, Guagnano GA, Kalof L (1998) A valuebelief-norm theory of support for social movements: the case of environmentalism. Hum Ecol Rev 6:81-97

Van Petegem P, Blieck A (2006) The environmental worldview of children: a cross-cultural perspective. Environ Educ Res 12(5):625-635

Vikan A, Camino C, Biaggio A, Nordvik H (2007) Endorsement of the New Ecological Paradigm: a comparison of two Brazilian samples and one Norwegian sample. Environ Behav 39:217-228

Wals AEJ (2007) Social learning: towards a sustainable world: principles, perspectives and praxis. Wageningen Academic Publishers, Wageningen

Wells NM, Lekies KS (2006) Nature and the life course: pathways from childhood nature experiences to adult environmentalism. Child Youth Environ 16:1-24

Wiegel R, Wiegel J (1978) Environmental concern. Environ Behav 10(1):3-15

Williams SM, McCrorie R (1990) The analysis of ecological attitudes in town and country. J Environ Manage 31:157-162

Zarger RK (2010) Learning the environment. In: Lancy D, Bock J, Gaskins S (eds) The anthropology of learning in childhood. AltaMira, Lanham 